\title{
Culturicon Design Model for Social Mobile Application
}

\author{
https://doi.org/10.3991/ijim.v14i05.13313 \\ Mohd Zhafri Mohd Zukhi \\ Universiti Teknologi MARA, Cawangan Kedah, Malaysia \\ Azham Hussain $\left.{ }^{\bowtie}\right)$, Husniza Husni \\ Universiti Utara Malaysia, Kedah, Malaysia \\ azham.h@uum.edu.my
}

\begin{abstract}
The usage of emoticon in computer-mediated communication has been growing rapidly among users, especially in social media. Emoticon has been used to express feelings, emotions, gestures, actions and places. Despite the growing number of emoticon users around the world, study on the cultural elements of the emoticon is still lacking. This research aims to propose a model for the development of Culturicon, which is Cultural-Based Emoticon. In doing so, a verification process must be done to the proposed model to ensure that the model is well verified. Expert review method was used for the verification method. Experts from the field of Human-Computer Interaction, User Experience and cultural study especially the academicians were chosen. In addition, application developer and graphic designer also were chosen as expert from the industry. The experts were approached by email and performed the verification by answering online questionnaire provided. The result obtained from these experts were analyzed and amendment were made based from the comments and suggestions. Results showed that $91 \%$ experts agreed the connections and flows of all components in the proposed model are logical and readable. Expert verification is important to ensure that the model is being develop correctly. By having this model, it can aid designer and developer in designing meaningful and effective culturicon.
\end{abstract}

Keywords-Emoticon, culture, expert review, human-computer interaction.

\section{$1 \quad$ Introduction}

Mobile messaging applications such as WhatsApp, Telegram, Facebook Messenger, Twitter and WeChat provide emoticon selection to be used for Computer-Mediated Communication (CMC). The usage of emoticon has evolved from time to time. At first, the usage of emoticon is created by Scott E. Fahlman in the form of ASCII symbols by using keyboard characters[1]. Then, the emoticon has evolved to the form of pictogram, such as the emoji and sticker[2]. Previous research has divided the category of emoticon into three categories: 
1) ASCII symbols, which are the emoticon made from keyboard character.

2) Preload Static Images, which are the cartoon images design by professionals.

3) Preload Dynamic Images, which are the short video or animation.

4) Local Upload Images, which are the images uploaded by the user[3].

These emoticons can show various expressions, from facial expressions to anything that relate to our daily lives such as cultural element.

The creation of emoticon brings a lot of benefit to the user for their communication in $\mathrm{CMC}$ because it helps the user to better express their emotion by providing better additional cues [4], strengthening the intensity of the message [5] and improve the efficiency of communication [6], [7]. These make the usage of emoticon become more popular day by day among heavy users of the mobile messaging application. Despite all these benefits, research has shown that emoticon also lacks in the terms of emoticon selection, emoticon misinterpretation and misused especially with people from different culture [8]-[10]. Due to this lacking, a Cultural-Based Emoticon (Culturicon) Design Model has been proposed to assist designer in designing appropriate Culturicon especially for Asian countries. The proposed model needs to be verified to ensure the development of the model is correct. Expert review method has been chosen for the verification process.

\section{Related Work}

Cultural models from other disciplines have been applied in Human-Computer Interaction (HCI) research. Among the cultural models that have been applied in HCI research are Hofstede Culture Model and Trompenaars Culture Model [11]. Research by Gould, Zakaria and Yusof used dimension of Power Distance and IndividualismCollectivism from Hofstede Culture Model and a dimension of Specific Relationship from Trompenaars Culture Model to compare representative's websites[12]. These dimensions were used to structure the differences between the cultures in Malaysia and United States during the usage of websites. They found these 2 cultures own their different ways of interacting and priorities.

Meanwhile, Callahan studied university's websites from 8 different countries using Hofstede Culture Model[13]. He compared the differences between cultures on the layout design, type and frequency of images and number of links per page of the university's websites. They found that there are correlations of logo image usage with dimension of high-Power Distance and figurative images usage with dimension of Masculinity. Dimension of Masculinity also was used in research by Dormann to overlook on the different emotions and values expressed on university website from three countries[14]. She found that the feminine countries expressed stronger feminine values as described in Hofstede Culture Model. Based from the related work, this research aims to apply the cultural models in designing emoticon to be used in CMC. 


\section{Model Development}

Based on the proposed initial model by [15], further study has been conducted to determine the suitable cultural dimension to represent Asian countries. In addition to that, characteristics of the emoticon created based on the model also were determined. As a result, the proposed model will come in 2 phases, Cultural Dimension (Phase 1) followed by HCI Icon Principle (Phase 2).

\subsection{Cultural dimension}

For Cultural Dimension, there are 3 cultural models considered in this research. They are Hall Culture Model[16], Trompenaars Culture Model[17], and Hofstede Culture Model[18]. After comparing these 3 models, it is found that some dimension from these 3 models are similar. Since the Hofstede Culture Model is the most popular among the other 2 models [11], researcher choose to use the naming of dimension from the Hofstede Culture Model. Hofstede Culture Model is popular because of its comprehensive framework, empirically confirmed and heavily cited. Table 1 below describes the cultural dimensions along with the trait and criteria.

Table 1. Cultural Dimension

\begin{tabular}{|c|c|c|}
\hline Cultural Dimension & Traits & Criteria \\
\hline \multirow[t]{8}{*}{ High Power Distance } & National & $\begin{array}{l}\text { Express national building, ruler building, historical building \& } \\
\text { places }\end{array}$ \\
\hline & Social Norm & Express privilege of authority \& those in power \\
\hline & Political & Express power of government \& military \\
\hline & Religion & Express the religion building $\&$ holy place. \\
\hline & Work & Express organization hierarchy \\
\hline & & Express that each role has its place \\
\hline & School & Express school hierarchy \\
\hline & & Express that teacher \& parent in command for teaching \\
\hline \multirow[t]{9}{*}{ High collectivism } & National & Express traditional games \& agriculture \\
\hline & & Express the extended family \& tribe \\
\hline & & Express national outfit \& culinary \\
\hline & Political & Express that law depends on ruler or group \\
\hline & Religion & Express celebrations, ceremonies \& ritual \\
\hline & Work & Fewer working hour \\
\hline & & Hiring \& promotion take in group status \\
\hline & School & Learning in group \\
\hline & & Student respect teacher \\
\hline \multirow[t]{7}{*}{$\begin{array}{l}\text { Low uncertainty } \\
\text { avoidance }\end{array}$} & Social norm & Open to change $\&$ innovation \\
\hline & & Tolerance for diversity \\
\hline & Political & High interest in politic \\
\hline & & Citizen protest are accepted \\
\hline & & Fewer \& general rules \& regulations \\
\hline & Religion & Many religion \\
\hline & & Little persecution for belief \\
\hline
\end{tabular}




\begin{tabular}{|l|l|l|}
\hline & & Each religion respect each other \\
\hline & School & Open-ended learning \\
\hline & Family & Fewer gender roles \\
\hline $\begin{array}{l}\text { Moderate } \\
\text { masculinity/femininity }\end{array}$ & Social norm & $\begin{array}{l}\text { M: Emphasis on money \& things } \\
\text { F: Emphasis on quality of life \& people }\end{array}$ \\
\hline & & $\begin{array}{l}\text { M: Live in order to work } \\
\text { F: Work in order to live }\end{array}$ \\
\hline & $\begin{array}{l}\text { M: Ego oriented } \\
\text { F: Relationship oriented }\end{array}$ \\
\hline & $\begin{array}{l}\text { Political \& } \\
\text { Economic }\end{array}$ & $\begin{array}{l}\text { M: Conflict solved through force } \\
\text { F: Conflict solved through negotiations }\end{array}$ \\
\hline & & $\begin{array}{l}\text { M: High priority for economic growth } \\
\text { F: High priority for environment protection }\end{array}$ \\
\hline & Work & $\begin{array}{l}\text { M: Prefer high pay } \\
\text { F: Prefer fewer working hour }\end{array}$ \\
\hline & School & $\begin{array}{l}\text { M: Prefer fewer women in management } \\
\text { F: Prefer more women in management }\end{array}$ \\
\hline & $\begin{array}{l}\text { M: Failing is seen as disaster } \\
\text { F: Failing is seen as minor accident }\end{array}$ \\
\hline & Family & $\begin{array}{l}\text { M: Girl cry, boy cannot cry } \\
\text { F: Both can cry }\end{array}$ \\
\hline & & $\begin{array}{l}\text { M: Boys fight, girls cannot fight } \\
\text { F: Both cannot fight }\end{array}$ \\
\hline Long-term Relationship & & Personal adaptability is important \\
\hline & Emphasis on persistent \\
\hline & Relationship are ordered by status \\
\hline & &
\end{tabular}

Table 1 shows Phase 1 of Culturicon Design Model which is the cultural dimension. Phase 1 consists of cultural dimension, trait and criteria. The level of the selected cultural dimensions are also stated which are high power distance [12], [18]-[20], high collectivism [12], [19]-[21], low uncertainty avoidance [12], [19], [20], moderate masculinity/femininity [12], [19] and long-term relationship [12], [19], [20]. In each of the dimensions, there are traits as the classification for the dimensions such as national, social norm, religion, political, work, school and family. In each trait is the criteria that suggest the element for the cultural dimension.

\subsection{Human-computer interaction icon principle}

The next part is Phase 2, which is the HCI Icon Principle. After determining the cultural element based on Phase 1, the next step is to design emoticon that fulfills the principle provided in the Phase 2. Table 2 depicts HCI icon principle and its criteria. 
Table 2. HCI Icon Principle

\begin{tabular}{|c|c|c|c|}
\hline $\begin{array}{l}\text { HCI Icon } \\
\text { Principle }\end{array}$ & Criteria & $\begin{array}{l}\text { HCI Icon } \\
\text { Principle }\end{array}$ & Criteria \\
\hline \multirow[t]{3}{*}{ Familiar } & User familiar with the design & Distinct & $\begin{array}{l}\text { Design are different to others to } \\
\text { avoid confusions }\end{array}$ \\
\hline & $\begin{array}{l}\text { Design are common in user's } \\
\text { environment }\end{array}$ & & $\begin{array}{l}\text { Every design is distinct from all } \\
\text { others }\end{array}$ \\
\hline & Applicable from real world knowledge & & $\begin{array}{l}\text { Distinguishing characteristics } \\
\text { are clear among set of } \\
\text { alternatives }\end{array}$ \\
\hline \multirow[t]{3}{*}{ Understandable } & $\begin{array}{l}\text { Spontaneously suggest the intended } \\
\text { concept }\end{array}$ & Unambiguous & $\begin{array}{l}\text { One design is associated with } \\
\text { one concept }\end{array}$ \\
\hline & $\begin{array}{l}\text { Strong association between Culturicon } \\
\text { and its concept }\end{array}$ & & $\begin{array}{l}\text { Additional cues to resolve } \\
\text { ambiguity }\end{array}$ \\
\hline & Meaning are based on direct association & & \\
\hline \multirow[t]{3}{*}{ Attractive } & Visually balance and stable & Memorable & Clearly identified by user \\
\hline & Proportion fit available space & & Striking and vivid \\
\hline & $\begin{array}{l}\text { Used harmonious colors, patterns and } \\
\text { values }\end{array}$ & & $\begin{array}{l}\text { Placed in the scheme of interface } \\
\text { is clear }\end{array}$ \\
\hline \multirow[t]{3}{*}{ Coherent } & $\begin{array}{l}\text { It is clear where one icon ends and } \\
\text { another begins }\end{array}$ & Legible & $\begin{array}{l}\text { Design is legible at reading } \\
\text { distance }\end{array}$ \\
\hline & $\begin{array}{l}\text { Focus and hold attention on subject } \\
\text { matter of the icon }\end{array}$ & & $\begin{array}{l}\text { Sufficient foreground- } \\
\text { background contrast }\end{array}$ \\
\hline & $\begin{array}{l}\text { Secondary design elements clearly } \\
\text { subdued relative to primary subject } \\
\text { matter }\end{array}$ & & \\
\hline \multirow[t]{4}{*}{ Informative } & Design concept are important & Extensible & Can be drawn smaller or bigger \\
\hline & Design does belong to category & & $\begin{array}{l}\text { Work in black and white as well } \\
\text { in colors }\end{array}$ \\
\hline & $\begin{array}{l}\text { User is able to interact by using it in } \\
\text { CMC }\end{array}$ & Compact & $\begin{array}{l}\text { Every object, line and pixel in } \\
\text { the design are necessary. }\end{array}$ \\
\hline & Assist user in expressing their intentions & & \\
\hline
\end{tabular}

\section{$4 \quad$ Methodology}

In verifying the culturicon design model, expert review method was chosen. The verification of the model was done by the experts from the related domain. The reason of expert review is chosen for the verification process is because expert review is fast, cheap, intuitive and easy to motivate people to do it and does not require advance planning [22], [23].

\subsection{Expert selection}

In order to appoint the experts, a letter of nomination was sent to the chosen experts through email to seek their acceptance to participate in the verification process. The verification process for Culturicon Design Model involved $4 \mathrm{HCI}$ experts, 2 culture experts, 2 arts and design experts, 1 application developer and 2 graphic designers from the industry, that make up 11 experts in total. The 11 experts chosen is sufficient as 
Nielsen and Molich suggest 3 to 5 experts to perform expert review [22]. The HCI, culture and arts and graphic design experts are academicians who are the faculty member of institutes of higher learning and practitioner with more than five years of experience. Meanwhile, the application developer and graphic designer experts come from the industry whom are also the expert that have at least 5 years of experience, as suggested by Rogers and Lopez [24]. Table 3 describes the demographic data of the selected experts.

Table 3. Demographic data of experts

\begin{tabular}{|l|l|l|c|}
\hline Expert (E) & \multicolumn{1}{|c|}{ Expertise } & Current Position & Years \\
\hline E1 & $\begin{array}{l}\text { Educational Multimedia, Persuasive Technology, User } \\
\text { Experience (UX) }\end{array}$ & Senior lecturer & 10 \\
\hline E2 & User Experience (UX), Virtual Heritage & Senior lecturer & 18 \\
\hline E4 & IT Management, HCI & IT Officer & 9 \\
\hline E5 & Socio-Culture, Arts & Lecturer & 12 \\
\hline E6 & Culture, Arts & Lecturer & 10 \\
\hline E7 & User Emotion and perception on Design Aesthetics & Senior Lecturer & 7 \\
\hline E8 & Fine Arts & Lecturer & 8 \\
\hline E9 & System Development & Developer & 10 \\
\hline E10 & Graphic Design & Graphic Designer & 7 \\
\hline E11 & Industrial and Graphic Design & Graphic Designer & 5 \\
\hline
\end{tabular}

\subsection{Verification process}

After the chosen experts agreed to participate in this verification process, another set of email were sent to them that contain the introduction about the research conducted, the instructions on doing the verification process, and the proposed model itself along with the online verification form link to answer questionnaire for verification process. The experts then reviewed and verified the model through the online questionnaire provided. After the expert reviewed and verified the model, the results and feedback were analysed, and amendment were made.

\subsection{Verification result}

There are 3 parts of verification that need to be answered by the experts. The first part is about the verification of the overall model, the second part is the verification on cultural dimension, and the third part is the verification on the HCI icon principles. 
Table 4. Verification of Overall Model

\begin{tabular}{|l|c|c|c|}
\hline \multirow{2}{*}{\multicolumn{1}{c|}{ Part }} & \multicolumn{3}{|c|}{ Frequency $(\mathrm{n}=\mathbf{5})$} \\
\cline { 2 - 4 } & $\begin{array}{c}\text { All proposed components } \\
\text { are relevant }\end{array}$ & Some may not be relevant & $\begin{array}{c}\text { All components are } \\
\text { not relevant }\end{array}$ \\
\hline Cultural Dimensions & 7 & 4 & - \\
\hline HCI Icon Principles & 9 & 2 & - \\
\hline
\end{tabular}

From Table 4, for the Cultural Dimension part, 7 experts domain agree that all proposed components are relevant while 4 domain experts indicated that some of the components in the Cultural Dimension may not be relevant. Meanwhile for the HCI Icon Principles part, 9 domain experts agreed that all proposed components are relevant and only 1 domain expert indicated some may not be relevant. Table 5 below shows the verification result of Cultural Dimension.

Table 5. Results of Component in Cultural Dimension

\begin{tabular}{|l|c|c|c|}
\hline \multirow{2}{*}{\multicolumn{1}{c|}{ Component }} & \multicolumn{3}{c|}{ Frequency (n = 5) } \\
\cline { 2 - 4 } \multicolumn{1}{c|}{} & $\begin{array}{c}\text { It is easy to } \\
\text { understand }\end{array}$ & $\begin{array}{c}\text { Need some } \\
\text { explanation }\end{array}$ & $\begin{array}{c}\text { Need very detail } \\
\text { explanation }\end{array}$ \\
\hline High Power Distance & 9 & 2 & - \\
\hline High Collectivism & 6 & 5 & - \\
\hline Low Uncertainty Avoidance & 6 & 4 & 1 \\
\hline Moderate Masculinity/Femininity & 7 & 3 & 1 \\
\hline Long-Term Relationship & 5 & 4 & 2 \\
\hline
\end{tabular}

Table 5 shows that 9 experts $(82 \%)$ agree that High Power Distance is easy to understand while 2 experts (18\%) indicated that the component need some explanation. For High Collectivism, 6 experts (55\%) agree that the component is easy to understand, while 5 experts $(45 \%)$ stated that it need some explanation. The result for Low Uncertainty Avoidance and Moderate Masculinity/Femininity are similar where 6 experts (55\%) agree that the component easy to understand, 4 experts $(36 \%)$ indicated that it needs some explanation and 1 expert (9\%) stated it needs very detail explanation. For the last component, Long-Term Relationship, 5 experts (45\%) agree the component is easy to understand, 4 experts (36\%) indicated that it needs some explanation and 2 experts $(18 \%)$ stated that it needs very detail explanation. Table 6 shows the verification result on HCI Icon Principle. 
Table 6. Results of Component in HCI Icon Principles

\begin{tabular}{|l|c|c|c|}
\hline \multirow{2}{*}{\multicolumn{2}{c|}{ Component }} & \multicolumn{3}{c|}{ Frequency (n=5) } \\
\cline { 2 - 4 } & $\begin{array}{c}\text { Easy to } \\
\text { understand }\end{array}$ & $\begin{array}{c}\text { Need some } \\
\text { explanation }\end{array}$ & $\begin{array}{c}\text { Need very detail } \\
\text { explanation }\end{array}$ \\
\hline Familiar & 9 & 2 & - \\
\hline Understandable & 9 & 2 & - \\
\hline Attractive & 10 & 1 & - \\
\hline Coherent & 6 & 5 & - \\
\hline Informative & 10 & 1 & - \\
\hline Distinct & 8 & 1 & 2 \\
\hline Unambiguous & 8 & 1 & 2 \\
\hline Memorable & 9 & 2 & - \\
\hline Legible & 7 & 4 & - \\
\hline Extensible & 9 & 1 & 1 \\
\hline Compact & 10 & 1 & - \\
\hline
\end{tabular}

As shown in Table 6, for the principle of Familiar, Understandable, Memorable, 9 experts $(82 \%)$ agree that it is easy to understand, while 2 experts $(18 \%)$ indicated it needs some explanation. For the component of Attractive, Informative and Compact, 10 experts (91\%) agree that it is easy to understand, while 1 expert $(9 \%)$ indicated it needs some explanation. For component of Distinct and Unambiguous, 8 experts (73\%) agree that it is easy to understand while 1 expert (9\%) indicated it needs some explanation and 2 experts $(18 \%)$ indicated it needs very detail explanation. For component of Coherent, 6 experts $(55 \%)$ agree that it is easy to understand while 5 experts (45\%) indicated that it needs some explanation. For component of Legible, 7 experts $(64 \%)$ agree that it is easy to understand while 4 experts $(36 \%)$ indicated that it needs some explanation. Lastly, component of Extensible, 9 experts (82\%) agree that it is easy to understand, while 1 expert (9\%) indicated that it needs some explanation and 1 expert (1\%) indicated that it needs very detail explanation.

As a part of verification process, experts may provide comments and feedback based on their perspective regarding the proposed model. Figure 1 and 2illustrate the feedback result on the overall proposed model.

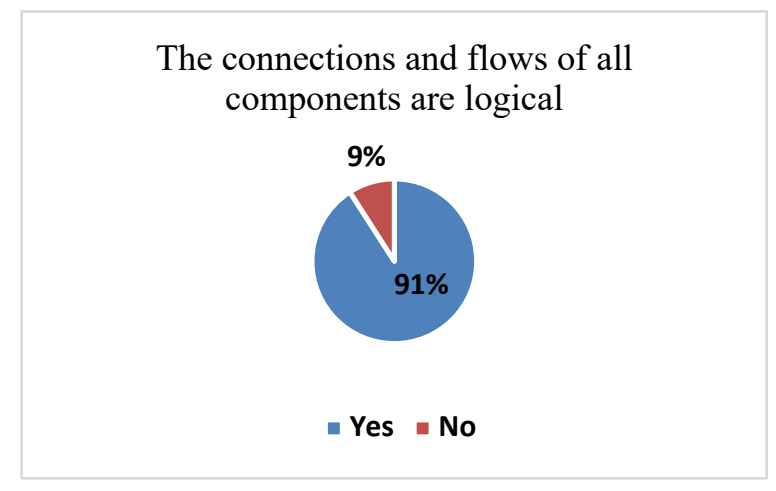

Fig. 1. The result of connection and flow of the model 
Overall, the proposed model is readable

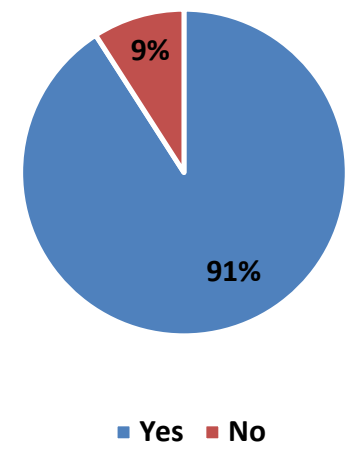

Fig. 2. The result of readability of the model

Figure 1 shows the result regarding the connection and flow of the model. 10 experts $(90 \%)$ agree that the connections and flows of the model are logical, while 1 expert $(9 \%)$ disagree. Figure 2 shows the result regarding the readability of the model. 10 experts $(90 \%)$ agree that the model is readable, while 1 expert $(9 \%)$ disagree.

For the last section, experts were asked to give any comment and suggestion regarding the proposed model. From the 11 experts, only 6 experts gave comments and suggestions as presented in Table 7 .

Table 7. Comments and Suggestion from Experts

\begin{tabular}{|c|c|c|}
\hline Element & Expert & Comments and Suggestion \\
\hline \multirow{3}{*}{ Component } & E1 & $\begin{array}{l}\text { Stated that there are too many components provided in the model and ask } \\
\text { whether all of these components are needed in developing Culturicon. } \\
\text { Need to enlarge the font size. }\end{array}$ \\
\hline & E5 & $\begin{array}{l}\text { Scope of culture is broad. The model needs to be more focused and precise } \\
\text { towards the culture it wants to express. }\end{array}$ \\
\hline & E11 & $\begin{array}{l}\text { Some components need explanations as they are hard to understand and to } \\
\text { interpret into graphical element. }\end{array}$ \\
\hline \multirow[t]{2}{*}{$\begin{array}{l}\text { Connection and } \\
\text { Flow of the } \\
\text { model }\end{array}$} & E1 & $\begin{array}{l}\text { Need to consider and identify the mandatory and optional components of } \\
\text { the model. Provide simple OD or legend for each component, provide } \\
\text { relationship between components to show clear connection. }\end{array}$ \\
\hline & E9 & Should provide process flow. \\
\hline \multirow[b]{2}{*}{ Overall } & E6 & Overall are good and interesting \\
\hline & E7 & $\begin{array}{l}\text { At this stage, description explained in words and it will be interesting } \\
\text { when designer begin to sketch the icon representing the cultural-based. } \\
\text { Agreed with the proposed model and will be interesting to see the findings. }\end{array}$ \\
\hline
\end{tabular}

As shown in Table 7, there are comments and suggestions regarding the components and the connection and flow of the model. For comment on the component in the model, 
E1 stated that there are too many components provided in the model, especially in the HCI Icon Principles where there are 11 principles provided. E1 suggested that some component need to be reviewed again whether they are needed in the model or not.

E5 stated that the actual cultural scope is broad to be fitted in the model. The model needs to be more focused and precise towards the culture it wants to express. The criteria need to have more detail on the culture of Asian countries so that the model really depicts its culture that make user easy to understand and use it as the guideline to create Culturicon. E11 commented that some components are difficult to understand due to lack of explanation, especially in the Cultural Dimensions part. E11 stated that some people are not familiar with the term used for the Cultural Dimensions.

For the flow of the model, E1 suggested that the model shows which component is mandatory and optional to ensure the flow of the model is clear. This is because, when user wants to use the model, user needs to choose either one or many components in the Cultural Dimensions, while for HCI Icon Principle, user need to fulfil all the principles. To overcome this, E1 suggested that the model provides legend for each component and relationship between components. E1 also stated that this model is significant in creating the Culturicon. E9 also stated give suggestion that there should be a process flow so that it will be easier for the user to understand how the model works. Lastly, for the overall comment on the model, E6 and E7 agreed that the model is good and interesting. E7 also agreed with the model and interested to see the finding of this research. The comments and suggestions received from these experts are taken into consideration for the modification of the model. These comments and suggestions were examined carefully, and the model were modified accordingly.

\section{$5 \quad$ Result and Discussion}

Based on the verification result, amendments were made in line with the experts' comments and suggestions. Figure 3 below shows the revised version of Culturicon Design Model.

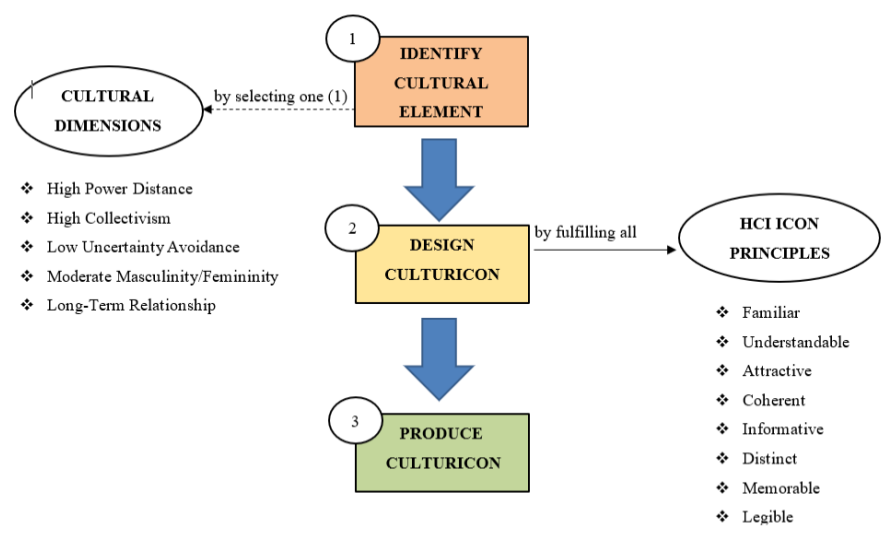

Fig. 3. Revised Culturicon Design Model 
The revised model has incorporated a process flow that makes it easier for user to follow, based on the suggestion from E1 and E9. By having the process flow, it helps user to acknowledge on how to use the model, where should they start first and what is the next step. The process flow starts with Phase 1 which is Identify Cultural Element. This phase is where user will choose either one or many cultural elements from the cultural dimensions provided. At least one cultural element must be selected. Next phase is Design Culturicon. For this phase, user need to fulfill all the HCI icon principles provided when designing Culturicon. There are 8 principles provided after amendment has been made. The design should take consideration from all 8 principles provided in the model. Next phase is Produce Culturicon. After user design the culturicon, they need to produce the culturicon based from the chosen cultural element and the design that fulfilled HCI Icon principles.

For the detail Culturicon Design Model, in Phase 1, there are changes for the traits and criteria that were made based from the suggestion by E5. These changes were made in order to accommodate the cultural perspective of certain Asian countries.

Table 8. Phase 1 Culturicon Design Model: Cultural Dimension

\begin{tabular}{|c|c|c|}
\hline \multicolumn{3}{|r|}{ Phase 1: Identify Cultural Element } \\
\hline $\begin{array}{c}\text { Cultural } \\
\text { Dimension }\end{array}$ & Trait & Criteria \\
\hline \multirow{7}{*}{$\begin{array}{l}\text { High Power } \\
\text { Distance }\end{array}$} & National & National building, ruler building \& historical building. \\
\hline & Social Norm & Privilege of authority \& those in power. \\
\hline & Political & Power of Royal Institution \& military (traditional/modern). \\
\hline & Religion & Religious building, holy places. \\
\hline & Work & Government \& Organization hierarchy (traditional/modern). \\
\hline & Education & School hierarchy. \\
\hline & Family & Young people respect elderly. \\
\hline \multirow{11}{*}{$\begin{array}{l}\text { High } \\
\text { Collectivism }\end{array}$} & \multirow{2}{*}{ National } & Traditional games \& agriculture. \\
\hline & & National outfit \& culinary. \\
\hline & \multirow{2}{*}{ Social Norm } & Obedient to custom \& rule. \\
\hline & & Value interpersonal harmony. \\
\hline & Political & Law depends on ruler or group. \\
\hline & Religion & Celebrations \& ceremonies. \\
\hline & \multirow{2}{*}{ Work } & Work in group \& support each other. \\
\hline & & Maintain harmony environment. \\
\hline & \multirow{2}{*}{ Education } & Learning in group. \\
\hline & & Student respect teacher. \\
\hline & Family & Extended family \& tribe. \\
\hline \multirow{9}{*}{$\begin{array}{l}\text { Low } \\
\text { Uncertainty } \\
\text { Avoidance }\end{array}$} & \multirow{2}{*}{ Social Norm } & Open to change \& innovation. \\
\hline & & Tolerance for diversity. \\
\hline & \multirow{2}{*}{ Political } & High interest in politics. \\
\hline & & Government changes are accepted. \\
\hline & \multirow{2}{*}{ Religion } & Many religions. \\
\hline & & Each religion respects each other. \\
\hline & \multirow{2}{*}{ Work } & Less loyalty. \\
\hline & & At ease with changing jobs. \\
\hline & Education & Open-ended learning. \\
\hline
\end{tabular}




\begin{tabular}{|c|c|c|}
\hline & Family & Fewer gender roles. \\
\hline \multirow{9}{*}{$\begin{array}{l}\text { Moderate } \\
\text { Masculinity \& } \\
\text { Femininity }\end{array}$} & \multirow{3}{*}{ Social Norm } & $\begin{array}{l}\text { M: Emphasis on money \& things. } \\
\text { F: Emphasis on quality of life \& people. }\end{array}$ \\
\hline & & $\begin{array}{l}\text { M: High priority for economic growth. } \\
\text { F: High priority for environment protection. }\end{array}$ \\
\hline & & $\begin{array}{l}\text { M: Ego oriented. } \\
\text { F: Relationship oriented. }\end{array}$ \\
\hline & Political & $\begin{array}{l}\text { M: Conflict solved through force. } \\
\text { F: Conflict solved through negotiation. }\end{array}$ \\
\hline & \multirow{2}{*}{ Work } & $\begin{array}{l}\text { M: Prefer high pay. } \\
\text { F: Prefer fewer working hour. }\end{array}$ \\
\hline & & $\begin{array}{l}\text { M: Prefer fewer women in management. } \\
\text { F: Prefer more women in management. }\end{array}$ \\
\hline & Education & $\begin{array}{l}\text { M: Failing is seen as disaster. } \\
\text { F: Failing is seen as minor accident. }\end{array}$ \\
\hline & \multirow{2}{*}{ Family } & $\begin{array}{l}\text { M: Girls cry, boys cannot cry. } \\
\text { F: Boys \& girls can cry. }\end{array}$ \\
\hline & & $\begin{array}{l}\text { M: Boys fight, girls cannot fight. } \\
\text { F: Boys \& girls cannot fight. }\end{array}$ \\
\hline \multirow{5}{*}{$\begin{array}{l}\text { Long-Term } \\
\text { Relationship }\end{array}$} & \multirow{2}{*}{ Social Norm } & Personal adaptability is important. \\
\hline & & Relationships ordered by status. \\
\hline & \multirow{2}{*}{ Work } & Emphasis on persistence. \\
\hline & & Leisure time not too important. \\
\hline & Family & Be thrifty. \\
\hline
\end{tabular}

For High Power Distance, $82 \%$ responded agree it is easy to understand, while $18 \%$ responded it need some explanation. Changes were made for Political and Work traits by adding additional information which is traditional/modern. This is to give an overview to user whether to design it in the context of traditional or modern element. For High Collectivism, 55\% responded it is easy to understand, while $45 \%$ responded it need some explanation. Changes were made to the trait of National, Social Norm, Work and Family. In National trait, the criteria of extended family and tribe were moved to trait of Family. Social Norm trait were added to add criteria of obedient to custom and rule and value interpersonal harmony. In trait of Work, the previous criteria were replaced with work in group and support each other and maintain harmony environment.

For Low Uncertainty Avoidance, 55\% respond easy to understand, 36\% responded it need some explanation and $9 \%$ responded it needs very detail explanation. Changes made for trait of Political, Religion and Work. In trait of Political, criteria citizen protest are accepted and fewer rules and regulation were replaced with government changes are accepted. In trait Religion, criteria little persecution to belief is removed. Trait of Work is added with the criteria less loyalty and at ease with changing job. For LongTerm Relationship, the trait Social Norm, Work and Family were added. The previous criteria were sorted accordingly. Criteria be thrifty is added to trait of Family. All the changes and amendments are made based from the suggestion by the E5, which is the cultural expert 
For Phase 2, changes made were: the omission of HCI icon principle of Unambiguous, Extensible and Compact based on the suggestion by E1. The omission of principle Unambiguous is because its criteria are similar with the principle Distinct. The principle Extensible was omitted because its meaning and criteria are similar with principle Informative and Legible. While principle Compact was omitted because it is not a critical principle in designing Culturicon. Table 9 below shows the details of the Culturicon Design Model.

Table 9. Phase 2 Culturicon Design Model: HCI Icon Principle

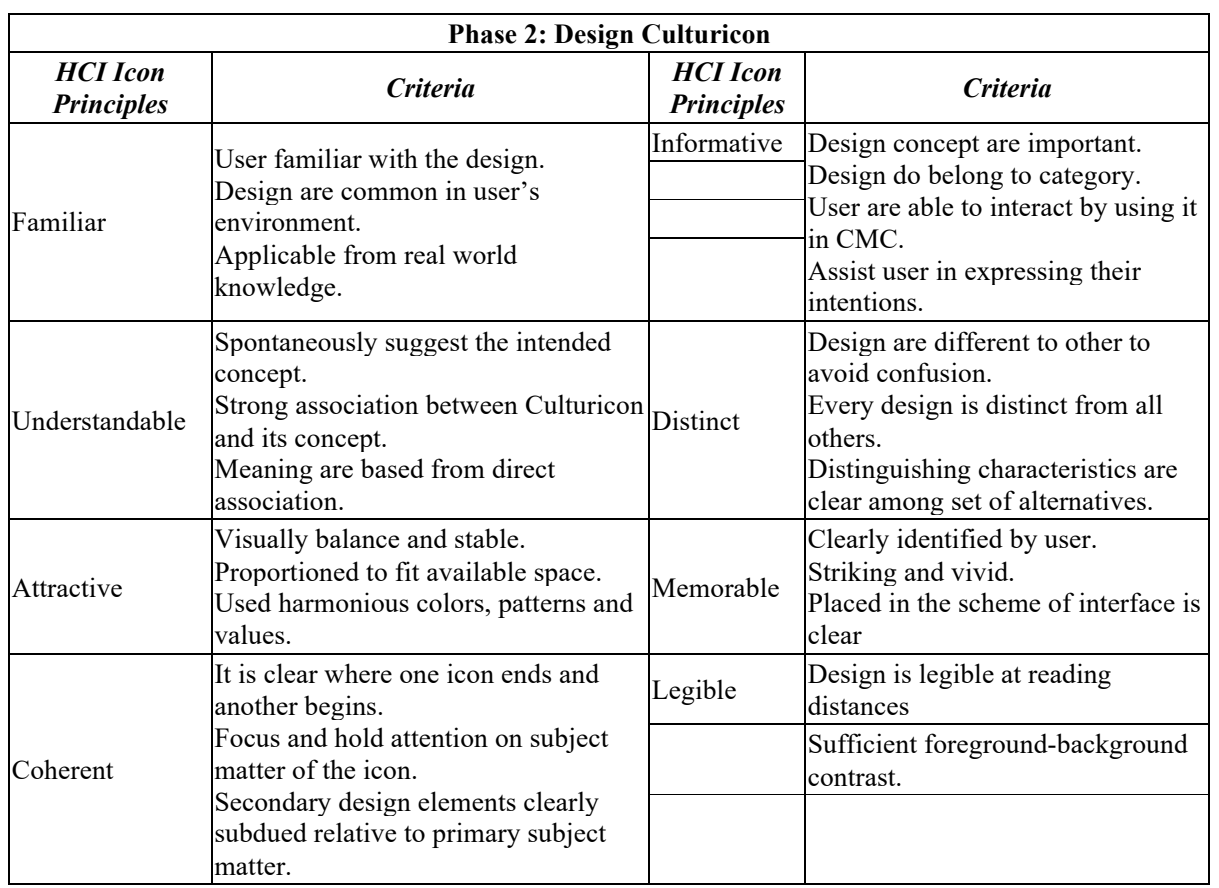

\section{Conclusion and Future Work}

Based from the suggestions and feedback from the expert, amendment have been made. This is to ensure that the model is being develop correctly. As this model contain cultural element, advice from the cultural expert was used as the guidance during the amendment process so that the cultural element can be suitable and appropriate with Asian countries as its target user. By correctly develop the proposed model, it can assist user, which is the designer in designing meaningful and effective Culturicon to be used by the mobile messaging user. After the proposed model has been verified through the expert review, next step is to perform the validation process. The verification process is to ensure the development of the model is right, while the validation process is to ensure the right model is developed. To perform the validation process, the target user, who is the designer needs to use this model to design the Culturicon. Then, after 
designer finished designing the sample Culturicon, the sample Culturicon will be used by the mobile messaging user in their mobile messaging application for their daily communication within a given time frame. A focus group session will be held once the given time frame ended to discuss the usefulness of the Culturicon developed.

\section{$7 \quad$ Acknowledgement}

This study was funded by Universiti Utara Malaysia under University Grant (SO Code: 13375).

\section{$8 \quad$ References}

[1] F. B. Krohn, "A GENERATIONAL APPROACH TO USING EMOTICONS AS NONVERBAL COMMUNICATION,” VOL. 34, NO. 4, PP. 321-328, 2004 https://doi.org/10.2190/9EQH-DE81-CWG1-QLL9

[2] K. Skovholt, A. Grønning, and A. Kankaanranta, "The communicative functions of emoticons in workplace e-mails :-),” J. Comput. Commun., vol. 19, no. 4, pp. 780-797, 2014 https://doi.org/10.1111/jec4.12063.

[3] Z. Cao and J. Ye, "Attention savings and emoticons usage in BBS," ICCIT 2009 - 4th Int. Conf. Comput. Sci. Converg. Inf. Technol., no. IV, pp. 416-419, 2009 https://doi.org/10. 1109/ICCIT.2009.112.

[4] D. Derks, A. E. R. Bos, and J. von Grumbkow, "Emoticons in computer-mediated communication: social motives and social context.," Cyberpsychol. Behav., vol. 11, no. 1, pp. 99-101, 2008 https://doi.org/10.1089/cpb.2007.9926.

[5] S.-K. Lo, "The nonverbal communication functions of emoticons in computer-mediated communication," Cyberpsychol. Behav., vol. 11, no. 5, pp. 595-597, 2008 https://doi.org/10.1089/cpb.2007.0132.

[6] Y.-J. Cha, "Identifying Cross-Cultural Differences of Emoticons in Computer-Mediated Communication: A Comparison of North American (US) and South Korean Emotional Responses to Emoticons,” 2007.

[7] T. Yuizono, J. Qi, and J. Munemori, "Effects of a Semantic Pamphlet for Pictogram Chat on Small Talk between Japanese and Chinese Speakers," 2012 Seventh Int. Conf. Knowledge, Inf. Creat. Support Syst., pp. 73-80, 2012 https://doi.org/10.1109/KICSS.2012.24.

[8] H. Miller, J. Thebault-Spieker, S. Chang, I. Johnson, L. Terveen, and B. Hecht, “'Blissfully happy' or 'ready to fight': Varying Interpretations of Emoji," Assoc. Adv. Artif. Intell., pp. 259-268, 2016.

[9] Y. Toratani and M. J. Hirayama, "Psychological analysis of emoticons used for e-mails on cellular phones," Int. Conf. Mob. IT Converg., pp. 49-53, 2011.

[10] S. Wijeratne, L. Balasuriya, A. Sheth, and D. Doran, "A Semantics-Based Measure of Emoji Similarity," 2017 https://doi.org/10.1145/3106426.3106490.

[11] L. Oshlyansky, "Cultural Models in HCI: Hofstede, Affordance and Technology Acceptance," p. 264, 2007.

[12] E. W. Gould, N. Zakaria, and S. A. M. Yusof, "Applying culture to website design: a comparison of Malaysian and US websites," Proc. IEEE Prof. Commun. Soc. Int. Prof. Commun. Conf. Proc. 18th Annu. ACM Int. Conf. Comput. Doc. Technol. teamwork, pp. 161-171, 2000. 
[13] E. Callahan, "Cultural Similarities and Differences in the Design of University Web sites," J. Comput. Commun., vol. 11, no. 1, pp. 239-273, 2005 https://doi.org/10.1111/ j.1083-6101.2006.tb00312.x.

[14] C. Dormann, "Cultural representations in Web design: Differences in emotions and values," People Comput. XIX - Bigger Pict. Proc. HCI 2005, pp. 285-299, 2006 https://doi.org/10. 1007/1-84628-249-7 18.

[15] M. Z. B. M. Zukhi, A. Hussain, and H. Husni, "A new model for cultural-based emoticon in distributed collective interaction via CMC," J. Telecommun. Electron. Comput. Eng., vol. 9, no. 2-12, 2017.

[16] T. E. Halls, The Silent Language. 1959.

[17] F. Trompenaars and C. Hampden-Turner, "Riding the Waves of Culture: Understanding Cultural Diversity in Business," 1997.

[18] G. Hofstede, "Dimensionalizing Cultures: The Hofstede Model in Context," Online Readings Psychol. Cult., vol. 2, no. 1, pp. 1-26, 2011 https://doi.org/10.9707/23070919.1014.

[19] R. Heimgärtner, "Using Converging Strategies to Reduce Divergence in Intercultural User Interface Design," J. Comput. Commun. vol. 05, no. 04, pp. 84-115, 2017https://doi.org/10.4236/jcc.2017.54006.

[20] J. Karreman and P. Romeo, "Cross-Cultural HCI and UX Design: A Comparison of Chinese and Western User Interfaces Investigating cultural factors behind WeChat and its Western counterparts," 2016.

[21] J. Miehle, K. Yoshino, L. Pragst, S. Ultes, S. Nakamura, and W. Minker, "Cultural Communication Idiosyncrasies in Human-Computer Interaction," Proc. 17th Annu. Meet. Spec. Interes. Gr. Discourse Dialogue, no. September, pp. 74-79, 2016 https://doi.org/10.18653/v1/W16-3610.

[22] J. Nielsen and R. Molich, "Heuristic Evaluation of User Interfaces," Proc. SIGCHI Conf. Hum. Factors Comput. Syst., no. April, pp. 249-256, 1990 https://doi.org/10.1145/ 97243.97281.

[23] H. Korhonen, "Comparison of Playtesting and Expert Review Methods in Mobile Game Evaluation,” Proc. 3rd Int. Conf. Fun Games, pp. 18-27, 2010 https://doi.org/10.1145/ 1823818.1823820 .

[24] [M. R. Hallowell and J. a. Gambatese, "Qualitative research: application of the delphi method to CEM research,” J. Constr. Eng. Manag., vol. 136, no. 1, pp. 99-107, 2010 https://doi.org/10.1061/(ASCE)CO.1943-7862.0000137.

\section{Authors}

Mohd Zhafri Mohd Zukhi is a lecturer at Universiti Teknologi MARA, Kedah. He interested on Human and Mobile interface design research. Email: zhafrimohd23@gmail.com

Azham Hussain is the Associate Professor of Software Engineering at UUM School of Computing. He is the founder and head of Human-Centered Computing Research Group which is affiliated with the Software Technology Research Platform Center at School of Computing, Universiti Utara Malaysia, 06010, Kedah, Malaysia. Assoc. Prof. Azham Hussain is a member of the US-based Institute of Electrical and Electronic Engineers (IEEE), and actively involved in both IEEE Communications and IEEE Computer societies. Azham is published in the areas of software evaluation and testing, 
user behaviours, group collaboration, and ubiquitous and mobile technology design. $\mathrm{He}$ has authored and co-authored more than 100-refereed technical publications, served as reviewer and referee for refereed journals and conferences on computing as well as the examiner for more than twenty doctoral and postgraduate scholars in his research areas. Email:azham.h@uum.edu.my

Husniza Husni is a senior lecturer at School of Computing, Universiti Utara Malaysia, 06010, Kedah, Malaysia and currently serves as Coordinator for Computing Professional Enrichment and Development Division (CoPED). She holds a Bachelor degree majoring in Artificial Intelligence (with Honours) from Universiti Utara Malaysia in 2002 and a Master degree in Computer Science from the University of Western Australia in 2005. Later, she received her her Ph.D. (Information Technology) from Universiti Utara Malaysia in 2010 and her doctoral work involves specific modeling of lexical model for dyslexic children's reading in Malay for the purpose of automatic speech recognition (ASR). She uses the major theory of dyslexia, the phonological deficit theory, to serve as fundamental in developing an ASR model specifically for dyslexic children's reading with attention given to the common reading patterns. Her research interest continue to grow in the realm of automatic reading tutor and interactive literacy education for useful educational technology to assist children with reading difficulties. Email: husniza@uum.edu.my

Article submitted 2019-12-19. Resubmitted 2020-01-29. Final acceptance 2020-02-02. Final version published as submitted by the authors. 